\title{
DEVELOPMENT OF A MODIFIED LIST FOR STANDARDIZED STUDY DESCRIPTIONS IN THE IMPLEMENTATION OF DOSE MANAGEMENT SYSTEMS IN RADIOLOGY
}

\author{
SOleEn Jaladet Alsofi* and Martin Fiebich ${ }^{* * *}$ \\ *Dept. of Biomedical Engineering, College of Engineering, University of Duhok, Kurdistan Region-Iraq \\ ** Dept. of Medical Physics, THM, Germany
}

(Received: October 8, 2019; Accepted for Publication: February 18, 2020)

\begin{abstract}
Diagnostic Radiology is an important field in medicine used as a diagnostic tool for diseases and injuries evaluation. However, exposure to high radiation doses could have negative impact on someone's health, therefore a dose management solution is needed to organize and coordinate the patient dose values. It is crucial to present the role of standardization study descriptions in the implementation of dose management systems in radiology. RadLex Playbook is one of the standardization study descriptions. With over 1000 CT scans the implementation of the mapping structure is very complicated. Therefore, a modified version is needed to reduce the number of examinations due to its possible problems through data mapping by suggesting a new list called "a reduced and embedded RadLex Playbook". To achieve this, three major systems were investigated. RIS (which was obtained from a German institute), DRL (using the German standardized study description) and RadLex Playbook. These systems were suggested to develop a strategy for data mapping and radiology procedure coded in different institutions. Direct mapping between RIS and DRL works only on specific institutionalized cases, therefore RadLex will act as an intermedium in between. Because RadLex has too many study descriptions, the suggested reduced list may help.
\end{abstract}

KEYWORDS: Radiology study descriptions, RadLex Playbook, Radiology Information System, Diagnostic Reference Level, Standardization, Dose management

https://doi.org/10.26682/sjuod.2020.23.1.6

\section{INTRODUCTION}

D iagnostic Radiology is a specific field in the medicine which is an important diagnostic tool for diseases and injuries evaluation. It has an integral part monitoring treatments and diagnostic outcome (Radiology E. S., 2009). Since early 1895 radiology and radiological technologies have been developed significantly to enhance the practice of diagnosis and routine clinical medicine. Radiologists are continuously improved and adopted new technologies which ensure patient's benefits as well as the whole healthcare system (Jeganathan et. al., 2014). It has also offered a scope of imaging procedures such as the computed tomography in order to gain images of the insides of the body organs (Radiology I. I., 2016).

Computed tomography (CT) as one of the useful techniques in diagnostic radiology has a very extensive scope of clinical functions; therefore, it is an important diagnostic method (Bosch de Basea et. al., 2015). The CT scanning is applicable for children and adults due to its profoundly shortened imaging time in comparison to various other techniques, e.g. Magnetic Resonance Imaging. During the last two decades the CT scanner availability has been expanded through the European countries and worldwide. Since then the awareness for its benefits as well as the side effects has been expanding constantly (Bosch de Basea et. al., 2015). However, the increase in the number of CT scan examinations has led to the subjection of patients to increased radiation doses ( Balkay et. al., 2013). To ensure adequate doses that a patient may receive in the different $x$-ray examinations, a quality management system should be employed (Bastião Silva et. al., 2014). Therefore, as a part of the quality management 
in many countries Diagnostic Reference Levels (DRL) has been established.

The DRL can be regarded as benchmarks for the optimization of patient protection and imaging which were introduced by the International Commission on Radiological Protection (ICRP) in the 1990s (COMMISSION, 2018). This was established in order to ensure that doses to which patients are subjected are as low as reasonably possible not only in $\mathrm{CT}$, but also in other radiological examinations in which the specified dose levels are not exceeding the accepted averages (Bastião Silva et. al., 2014). To increase the levels of safety, a management solution is needed to organize and coordinate the individual patient dose values which were mostly collected manually until recently. By applying dose management, tracking the radiation doses for reviewing and optimizing purposes may be possible ( Parakh et. al., 2016). However, each radiology department in different institutes has their own list of procedure descriptions and internal codes. These internal codes are also related to a corresponding image procedure where an associated physician can select from whenever a new imaging study is needed. Since these codes and descriptions are created at an institutional level instead of a regional or even at national level, it results in a set of institution-specific procedures. Hence obstacles occur when the same or similar examination is performed in another institute which results in different codes and descriptions. This complicates interoperability, data sharing and cross institution data analytics efforts ( Mabotuwana et. al., 2014). A proper dose management can be used to control and prevent the increase of radiation risks; therefore, it is crucial to present the role of standardization study descriptions in the implementation of dose management systems in radiology. This is further needed for the development of standardization and optimization in order to achieve Low-Dose, which is based on the principles of "As Low As Reasonably Achievable" (ALARA) (The Diagnostic
Reference Levels (DRLs) in Europe, 2007) \& (Kavanagh et. al. , 2018). It is a big challenge to name imaging procedures since there are not standards across institutes, therefore, the Radiological Society of North-America has developed a list called RadLex Playbook (Mabotuwana et. al., 2014). This list contains over 1000 CT scan variety examination study description types which made the implementation of the mapping structure very hard and complicated to be collaborated with. The aim of the present work is to suggest a modification of the RadLex Playbook by reducing the immense number of examinations due to its possible problems through data mapping. This is sought in order to make it more applicable and thus may be suggested as a new list called "a reduced and embedded RadLex Playbook". This reduced list might help to find a proper way to map institution-specific Radiology Information System data to the Diagnostic Reference Level values which are standard at national level only. This modification is applied on a German study case by using the German Diagnostic Reference Level.

\section{MATERIALS AND METHODS}

In this work, three major systems including the Radiology Information System, the Diagnostic Reference Level value and the RadLex Playbook were considered and used in order to suggest and develop a strategy for data mapping and radiology procedure coding in institutions.

\section{Radiology Information System}

The RIS is a database used by radiologists to create and store a patient's medical data (Nitrosi et. al., 2014). The RIS data, which has been used as a study case in this work, was obtained from a German institute (clinic), which contained valuable information such as the patient ID, gender, age, protocol name or examination type, examination date and time, body region, CTDIvol, DLP etc. as shown in table 1. 
Table (1):The RIS from a German institute

\begin{tabular}{|c|c|c|c|c|c|c|c|c|c|c|c|c|c|c|}
\hline Gender & \begin{tabular}{|l|l|} 
Patient.ID \\
\end{tabular} & \begin{tabular}{l|l} 
Age & Examinatin Date \\
\end{tabular} & Examination Time & Number of Series & Manufiacturer & Device Model & Total DLP(mGjcm) & Protocol Name or Examination Type & Series Time & BodyPart & Avg. CTDlvol.(mGy) & $\begin{array}{ll}D L P(m G y c m) \\
\end{array}$ & KVp & Tube Storm(mA) \\
\hline \begin{tabular}{|l|l|l|l|l|l|l|l} 
\\
\end{tabular} & 1,191,597 & $54 / 20180404110$ & $12.41: 33$ & & 3 Philips & Ingenuty CT & 1528. & 8 CCT Head & $12: 42.28$ & ERAIII & 54.6 & 764.4 & 120 & 300 \\
\hline W & $9,059,062$ & 69201810405 & 19:31:19 & & 4/Philps & IngenuityCT & & Thorar nativ Thorar & 19:33:13 & CHEST & 9.4727 & 332.4893 & 120 & 255 \\
\hline WI & $1,969,196$ & $57 / 2018004110$ & 13:07:16 & & 7/Philips & Billiance 16 & & Abdomen nativabdomen & $13: 09: 23$ & None & 10.5 & & 120 & 186 \\
\hline II & $1,255,873$ & 75201800406 & $14: 55: 15$ & & 4/Philips & Ingernuty CT & 1473.1148 & gAddomen nativilAdomemen & $14: 57: 31$ & ABDOMEN & 7.2976 & 341.52295 & 120 & 165 \\
\hline WI & $1,968,476$ & 592018004110 & $12: 28.34$ & & 4 Philips & Ingenulty CT & 7928.8682 & 5 Thorax Bollus/Abd.p.p. Thorax & $1233: 47$ & CHEST & 5758 & 264.2895 & 120 & 272. \\
\hline WI & $1,968,476$ & 5920180041110 & $12: 28.34$ & & 4/Philips & Ingernuty CT & 792.868 & 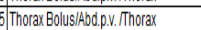 & $12: 33: 46$ & CHEST & 5.758 & & 120 & 272 \\
\hline WI & $1,968,476$ & $592018004 / 10$ & 12:28:34 & & 4 Philps & Ingenuly CT & 1042.079 & 7 Thorax Bolus/Abdod.p.y. Thorax & $12: 35: 02$ & ABDOMEN & 7.3283 & 347.3599 & 120 & 408 \\
\hline Wi & $9,069,356$ & $7120180441 / 0$ & $12: 15.52$ & & 4 Philips & Ingenuly CT & 1208.902 & 2 Thorax Bolus/Abdop.p. . Thorax & 12.20 .46 & CHEST & 9.949 & 402.9674 & 120 & 168 \\
\hline III & $1,977,260$ & $43201810041 / 10$ & $11: 49.03$ & & 3 Philips & IngernutycT & 1662 & 2 CCT Head & $11: 50: 37$ & ERAIN & 55.4 & 831 & 120 & 300 \\
\hline M & $1,969,932$ & 602018004110 & 11:14:13 & & 5 Philips & Brilliance 16 & 3062.92 & 2 Herd-Neck AngiolCTA & 11:19:17 & CAROTD & 5.6558 & 168.675 & 120 & 469 \\
\hline W & $1,969,932$ & 6020181004110 & 11:14:13 & & 5 Philips & Brilliance 16 & 3062.82 & 2 HeadodNeck AngiolctA & $11: 18: 23$ & None & 2.3 & 2.76 & 120 & 90 \\
\hline III & $\begin{array}{ll}1,9002,856 \\
\end{array}$ & $8720180041 / 10$ & $11: 10: 16$ & & 9. Philips & Ingernity CT & 1801.0902 & 24 Phlasen Livel/Fancieas / Aaboomen & $11: 15: 37$ & ABDOMEN & 5.5332 & 132.797 & 120 & 85 \\
\hline WI & $1,962,856$ & 8720181804110 & 11:10:16 & & 9 philips & Ingerulty CT & 1801.0902 & 25 Phasen Liverifancreas / Abdomen & $11: 14: 32$ & ABDOMEN & 8.0233 & 182.9303 & 120 & \\
\hline WI & $1,277,251$ & $31 / 2018004110$ & $13: 59: 42$ & & 3 Philips & |ngenulty CT & & Thorax KM Thorax & $14: 06: 39$ & CHEST & 17.60869 & & 120 & 441 \\
\hline W & $1,322,116$ & 852018004110 & 10:51:07 & & 2philips & Brilliance 16 & & 6 None & $10: 51: 36$ & None & 0 & 0 & & 30 \\
\hline III & $1,977,238$ & $21120180041 / 10$ & $02: 3227$ & & 5 Philips & Brilliance 16 & 388.158 & 6 Thoras CMThorax & $02: 35: 13$ & None & 3.5685 & & 120 & 87 \\
\hline in & $9,072,272$ & 62201800409 & $13: 51.58$ & & 3 Philips & Ingernutyct & 1508.7822 & 5 Thorax Eolus/Abdop.p. Therax & $13: 58: 16$ & ABDOMEN & 10.8157 & 502.9275 & 120 & 270 \\
\hline III & $9,025,900$ & 592018010409 & $13: 23.13$ & & 4 |Philps & Brilliance 16 & 1269. & g) Thorax Bolus Abd. pvilfdomen & $13: 25: 40$ & None & & & 120 & 225 \\
\hline WI & $1,743,357$ & 7720181040409 & $12: 58: 59$ & & 3/Philips & Ingerulty CT & & 4CCT Kopf & $13: 00: 04$ & ERAIN & 54.8 & & 120 & 300 \\
\hline WI & $1,841,040$ & 69201800409 & $10: 01: 16$ & & 4 Philips & Brilliance 16 & 5566.44 & 4 Pestis- - leg - AngiolCTA & $10: 02: 03$ & None & & & 120 & 50 \\
\hline
\end{tabular}

To start the mapping procedure, the information taken from the data base included the protocol name which illustrate the examination study description, the body region showing which body part has been examined and the two important indexes; the volume weighted CT dose index $\left(\mathrm{CTDI}_{\mathrm{vol}}\right)$ measured in mGy and the dose length product (DLP) measured in mGycm which are known as dosimetric indexes (Nakada Y et. al., 2018). In this work, five samples were selected from table 1 including (CCT/Head, Thorax native/Thorax, 4 Phases Liver/Pancreas/Abdomen, Abdomen native/Abdomen and Head-Neck-Angio/CTA). For each sample examination type, the length (L) of the CT scan was manually calculated using the following equation (BUSHBERG et. al., 2012):

$$
D L P=C T D I_{v o l} \times L
$$

The data obtained using this equation was used later in the following steps of this procedure.

\section{Diagnostic Reference Level}

The DRL is a measure of optimization for radiation protection (Richard Veit, and Burkhard Bauer, 2019), which help avoiding unnecessarily high doses to the patient due to its brief imaging time, therefore, it is applicable for children and adults (Richard Veit, and Burkhard Bauer, 2019) \& (Commission, 1999). In this paper, it was focused on adults alone using the German standardized study description as shown in table 2 (Stamm et. al., 2017). 
Table (2): Diagnostic Reference Level values for adult CT scans

\begin{tabular}{|l|r|r|}
\hline Examination Type & CTDIvol (mGy) & DLP(mGycm) \\
\hline Head (brain) & 60 & 850 \\
\hline Facial bones & 20 & 200 \\
\hline Paranasal sinusitis & 8 & 90 \\
\hline Neck (facial skull till aortic arch) & 15 & 330 \\
\hline CT-Angiography of carotid & 20 & 600 \\
\hline Cervical spine (intervertebral disc) & 25 & - \\
\hline Cervical spine (bones) & 20 & 300 \\
\hline Chest (inclusive adrenal gland) & 10 & 350 \\
\hline Lungs (high contrast, folloe up) & 3 & 100 \\
\hline Chest and upper abdomen (inclusive pelvis entrance) & 10 & 450 \\
\hline CT-Angiography of the entire aorta & 13 & 800 \\
\hline Prospective ECG-triggered coronary angiography & 20 & 330 \\
\hline Upper abdomen & 15 & 360 \\
\hline Abdomen with pelvis & 15 & 700 \\
\hline Torso (Chest+ abdomen + pelvis) & 13 & 1000 \\
\hline Lumbar spine (intervertebral disc) & 25 & - \\
\hline Lumbar spine (bone) & 10 & 180 \\
\hline Pelvis (soft tissue) & 15 & 400 \\
\hline Pelvis (bones) & 10 & 260 \\
\hline CT-Angiography pelvis - leg & 8 & 1000 \\
\hline
\end{tabular}

The DRL standardized table contained the examination region or the protocol name and the two dosimetric indexes. Measuring the length in the DRL was carried out using equation (1).

This procedure also involved matching between the RIS and the DRL through mapping examinations types in the RIS data base and compared with the examinations type or region in the DRL table. The comparison was done according to the similarity between the protocol type and the body region through measuring two main and important points; the first point was between the $\mathrm{CTDI}_{\mathrm{vol}}$ values in both RIS and DRL, where the dose value in the RIS must be almost within the same range of the dose value as in the DRL or less and trying not to exceed it. This concern is raised due to the potential harm to a patient which can be caused regardless how small the radiation dose may be (Ozasa $\mathrm{K}$ et. al., 2011) \& (Council, 2006). The second point was comparing the length of the body region in both RIS and DRL, where the values must almost be also at same range. This mapping procedure represented as a direct mapping method between both RIS and DRL.

\section{RadLex Playbook}

The RadLex Playbook is another standardized method that was developed and released by the Radiological Society of North America (RSNA) ((RSNA), RadLex radiology lexicon, 2017). The Playbook aims to provide a standard system for naming radiology procedures based on the attributes which define an imaging exam such as MODALITY, MODALITY_MODIFIER, BODY_REGION, LATERALITY, REASON_FOR_EXAM, PHARMACEUTICAL, etc. as shown further in table 3 providing standard names and codes for radiologic studies (Mabotuwana et. al., 2014) \& (Wang et. al., 2017). Playbook is intended to facilitate a variety of operational and quality improvement efforts ((RSNA), RadLex radiology lexicon, 2017) \& (Wang et. al., 2017). 
Table (3): The RadLex Playbook 2.3

\begin{tabular}{|c|c|c|c|c|c|c|c|c|c|c|}
\hline PROTOCOL_NAME & MODALITY & POPULATION & BOOY_REGION & MODALTY_MOOIFER & PROCEDURE_MOOFIER & ANATOMIC_FOCUS & LATERALITY & REASON_EOR_EXAM & TECHNIQUE & PHARMACEUTCAL \\
\hline CT ABD ANGIO WO \& W IYCON & ст & & ABCOUEN & ANGIDGRAPHY & & & & & & WTHOUT THEN WTH IV CONTRAST \\
\hline CT GUIDE ABLAT & CT & & & GUIDANCE & & & & ABLATION & & \\
\hline CT SPINE GUIDE VPLASTY & ct & & SPNNE & GUIDANCE & & & & VERTEQROPLASTY & & \\
\hline CTSTERTXS & CT & & & STEREOTACTIC & & & & & & \\
\hline CT SPINE DENSTO & CT & & SPINE & DENSTOMETRY & & & & & & \\
\hline CTHEAD DENTASCAN & CT & & HEAD & DENTAL SCAN & & & & & & \\
\hline CT GUIDE NEEDLE PLCMNT & ст & & & GUIDANCE & & & & NEEDLE PLACEMENT & & \\
\hline CTMULTIPLANREF & CT & & & & MULTIPPLLANAR REFORUATION & & & & & \\
\hline CTPELVIS PLVITTRY & ст & & PELVIS & PELUMETRY & & & & & & \\
\hline CTHEAD IAC WO \& W WCON & CT & & HEAD & & & IINTERNAL AUDITORY CANAL & & & & WTHOUT THEN WTH I I CONTRAST \\
\hline CTHEAD SELLAWO \& WIVON & CT & & HEAD & & & SELLA TURCICA & & & & WTHOUT THEN WTH IV CONTRAST \\
\hline CTBONEDENSTO & ст & & BONE & DENSITOMETRY & & & & & & \\
\hline CT ABD PELVIS COLONGRPHY SCREEN & ct & & ABCOMEN & COLONOGRAPHY & & & & SCREENNG & & \\
\hline CTABD PELVIS COLONGRPHYWOINCON & CT & & ABCOMEN & COLONOGRAPHY & & & & & & |MTHOUT N CONTRAST \\
\hline CT & CT & & & & & & & & & \\
\hline CT ABD PELVIS COLONGRPHYW WVON & ct & & ABCOMEN & COLONOGRAPHY & & & & & & WTH I CONTRAST \\
\hline CTHEAD IAC WO NCON & CT & & HEAD & & & $\begin{array}{l}\text { IINTERNAL AUDITORY CANAL } \\
\end{array}$ & & & & WTHOUT IV CONTRAST \\
\hline CTHEAD IAC WIVCON & ст & & HEAD & & & \begin{tabular}{|l|l|} 
INTERNAL AUDITORY CANAL \\
\end{tabular} & & & & |WTHIV CONTRAST \\
\hline CTBONE GUIDE RAD ABLAT & CT & & BONE & GUIDANCE & & & & RADIOFREQUENCY AELATION & & \\
\hline CT ABD GUIDE RETRO BX & CT & & ABCOMEN & GUIDANCE & & RETROPERTONEUN & & BlOPSY & & \\
\hline CTHEAD PERFUS W IVCON & CT & & HEAD & PERFUSION & & & & & & WTH IV CONTRAST \\
\hline CTHEAD SINUSES WO \& W IICON & ст & & HEAD & & & PARANASAL INUUSES & & & & WTHOUT THEN WTH IV CONTRAST \\
\hline
\end{tabular}

The RadLex Playbook list version (2.3) shown in table 3, has been used in this work which contains more than $1000 \mathrm{CT}$ scan examination study description (RSNA Informatics, 2017) \& (Informatics, 2016). To facilitate the procedure by limiting and reducing some of these CT examination studies, a new extracted list from the original list was suggested forming the third main part of this work. In this reduced list it has been focused only at the required attributes: the PROTOCOL NAME, LATERALITY and PHARMACEUTICAL \& PHASES as shown in table 4. Each of these attributes included values that were extracted from the list of Playbook excel sheet. For instance, the PROTOCOL NAME contains the EXANINATION STUDY DESCRIPTON, the LATERALITY contains of three possibilities values (LEFT, RIGHT and BILATERAL) and the PHARMACEUTICAL \& PHASES, which indicates administration of contrast material, including route of administration and the possibility of performing a multiphases. These values are WITH IV CONTRAST (W), WITHOUT IV CONTRAST (WO), WITHOUT AND WITH IV CONTRAST (BOTH), ORAL CONTRAST and RECTAL CONTRAST.

Table (4): The RadLex Playbook excel template

\section{EXAMINATION STUDY DESCRIPTION (PROTOCOL_NAME)}

To summarize the strategy for reducing the list, it was prepared according to many different points. For instance, by eliminating and neglecting the protocols that didn't contain or involve any body regions or describe exactly which body part meant to be. Another point was by disregarding the protocols that performed types of processing or techniques by applying the same CT exam without editing that kind of processing or techniques. Excluding the protocols that mentioned low doses which had the similar exam type without the expression of

\section{LATERALITY PHARMACEUTICAL (IV CONTRAST) \& PHASES}

low doses, where both protocols could be performed as one exam type because all CT scans had to follow the regulations of quality control in radiology dose management (Morin RL, 2014) which had to be all in the range of low doses. Excluding the protocols that edit limitation to a body region or to any kind of procedure which is similar in result for the same protocols without limitation. Examples for each of the above suggested points are shown in table 5. 
Table (5): Examples of elimination of the examination types

\begin{tabular}{|l|}
\hline EXAMINATION STUDY DESCRIPTION (PROTOCOL_NAME) \\
\hline CT ANGIOGRAPHY WITH IV CONTRAST \\
\hline CT BONE \\
\hline CT ABDOMEN 3D IMAGING PROCESSING WITHOUT IV CONTRAST \\
\hline CT CERVICAL SPINE GUIDANCE WITHOUT IV CONTRAST \\
\hline CT CHEST ABDOMEN PELVIS LOW DOSE WITH IV CONTRAST \\
\hline CT CHEST LIMITED \\
\hline CT CHEST LIMITED NODULE DUAL ENERGY CT \\
\hline
\end{tabular}

One of the suggestion points that helped to reduce a good amount of those protocols was to merge protocols according to their classification's categories; the PHARMACEUTICAL (IV CONTRAST) \& PHASES attribute with illustrating and indicating its IV CONTRAST \& PHASES in the category as (W, WO, BOTH, MULTIPHASE). Similarly, it was implemented for the LATERALITY attribute by mentioning the LATERLITY category (LEFT, RIGHT, BILATERAL) as shown in table 6.

Table (6a): Examples of the examination types (protocols) before merging

\begin{tabular}{|l|l|l|}
\hline EXAMINATION STUDY DESCRIPTION (PROTOCOL_NAME) & LATERALITY & PHARMACEUTICAL (IV CONTRAST) \& PHASES \\
\hline CT ABDOMEN PANCREAS & & W \\
\hline CT ABDOMEN PANCREAS WITH IV CONTRAST & & BOTH \\
\hline CT ABDOMEN PANCREAS WITHOUT THEN WITH IV CONTRAST & & WO \\
\hline CT ABDOMEN PANCREAS WITHOUT IV CONTRAST & MULTIPHASE \\
\hline CT ABDOMEN MULTIPHASE PANCREAS WITHOUT THEN WITH IV CONTRAST & W \\
\hline CT CHEST PELVIS LOWER EXTREMITY WITH IV CONTRAST & BOTH \\
\hline CT CHEST PELVIS LOWER EXTREMITY WITHOUT THEN WITH IV CONTRAST & \\
\hline CT LOWER EXTREMITY ANGIOGRAPHY & & \\
\hline CT LOWER EXTREMITY ANGIOGRAPHY BILATERAL & BILATERAL & \\
\hline CT LOWER EXTREMITY ANGIOGRAPHY LEFT & LEFT & \\
\hline CT LOWER EXTREMITY ANGIOGRAPHY LEFT WITHOUT THEN WITH IV CONTRAST & LEFT & BOTH \\
\hline CT LOWER EXTREMITY ANGIOGRAPHY RIGHT & RIGHT & \\
\hline CT LOWER EXTREMITY ANGIOGRAPHY RIGHT WITHOUT THEN WITH IV CONTRAST & RIGHT & BOTH \\
\hline CT LOWER EXTREMITY ANGIOGRAPHY WITH IV CONTRAST & & W \\
\hline CT LOWER EXTREMITY ANGIOGRAPHY WITHOUT THEN WITH IV CONTRAST & & BOTH \\
\hline
\end{tabular}

Table (6b): Examples of the examination types (protocols) after merging

\begin{tabular}{|l|l|l|}
\hline EXAMINATION STUDY DESCRIPTION (PROTOCOL_NAME) & LATERALITY & PHARMACEUTICAL (IV CONTRAST) \& PHASES \\
\hline CT ABDOMEN PANCREAS & & W.WO.BOTH,MULTIPHASE \\
\hline CT CHEST PELVIS LOWER EXTREMITY & & W,BOTH \\
\hline CT LOWER EXTREMITY ANGIOGRAPHY & LEFT,RIGHT,BILATERAL & W,BOTH \\
\hline
\end{tabular}

There were other arguments for eliminating more protocols or examination study descriptions that were already covered with other similar protocols which could be considered as one protocol as shown in table 7. 
Table (7): Examples of elimination of the examination types before \& after

\begin{tabular}{|l|}
\hline EXAMINATION STUDY DESCRIPTION (PROTOCOL_NAME) \\
\hline CT ABDOMEN BIOPSY \\
\hline CT ABDOMEN BIOPSY NEEDLE \\
\hline CT ABDOMEN PELVIS ANGIOGRAPHY \\
\hline CT ABDOMEN PELVIS ANGIOGRAPHY DUAL ENERGY CT \\
\hline CT ABDOMEN LIVER \\
\hline CT ABDOMEN LIVER DONOR \\
\hline
\end{tabular}

\begin{tabular}{|l|}
\hline EXAMINATION STUDY DESCRIPTION (PROTOCOL_NAME) \\
\hline CT ABDOMEN BIOPSY \\
\hline CT ABDOMEN PELVIS ANGIOGRAPHY \\
\hline CT ABDOMEN LIVER \\
\hline
\end{tabular}

After applying all those suggestions and arguments on the original RadLex Playbook list, a modified and reduced list has been developed. The protocols in the modified reduced RadLex Playbook list in this work was attempted to be mapped to the most appropriate and suitable DRL examination types according to the body regions. For example, the examination type " $\mathrm{CT}$ ABDOMEN" which was mapped to the examination type "Upper abdomen" in the DRL. In case of a protocol contained more than one body region for example: "CT ABDOMEN PELVIS" was mapped to the "Abdomen with pelvis "in the DRL. In other situations where protocols had an additional procedure or special processing with the body region such as the ANGIOGRAPHY procedure for example: "CT ABDOMEN ANGIOGRAPHY" was mapped to "CT-Angiography of the entire aorta" in the DRL. Those cases or examples were covered with a single DRL examination type. This study also included protocols that needed and required more than one single DRL for instance: "CT HEAD CHEST BRAIN" which was mapped to two DRL categories, the "Head (Brain)" category and "Chest (inclusive adrenal gland)" category.
The final consideration in this procedure was to apply the suggested reduced list as convenient standardized study description method in order to map between the entities of the RIS and the DRL. The mapping was done at first by applying the suggested reduced list directly to the DRL and matching them to find a standard mapping method that could be applied with different entities of RIS.

\section{RESULTS AND DISCUSSION}

The results and discussion using the five selected samples from the RIS excel sheet and their applications in the three systems (RIS, DRL and RadLex) obtained in this work are described in the same sequence as written in the methods \& materials.

\section{RIS and DRL mapping}

The results of the calculated length of the CT scan for the five RIS samples using the mentioned equation are presented in table 8 . This table also contains the calculated DRL length values of their matching examination type. 
Table (8): The direct mapping between both the RIS and DRL

\begin{tabular}{|c|c|c|c|c|c|c|c|c|}
\hline Examination Type & Body Part & Avg.CTDlvol.(mGy) & $\mathrm{DLP}(\mathrm{mG} \mathrm{ycm})$ & Length $(\mathrm{cm})$ & DRL & CTDlvol.(mGy) & $\mathrm{DLP}(\mathrm{mGycm})$ & Length $(\mathrm{cm})$ \\
\hline CCT/Head & BRAIN & 54.6 & 764.4 & 14 & Head (Brain) & 60 & 850 & 14.2 \\
\hline Thorax nativ $/$ Thorax & CHEST & 9.4727 & 332.4893 & 35.1 & Chest (inclusive adrenal gland) & 10 & 350 & 35 \\
\hline 4 Phases Liver/Pancreas /Abdomen & ABDOMEN & 5.5332 & 132.797 & 24 & Upper abdomen & 15 & 360 & 24 \\
\hline Abdomen nativ /Abdomen & ABDOMEN & 7.2976 & 341.5295 & 46.8 & Abdomen with pelvis & 15 & 700 & 46.7 \\
\hline Head-Neck-Angio /CTA & CAROTID & 5.6558 & 169.675 & 30 & CT-Angiography of carotid & 20 & 600 & 30 \\
\hline
\end{tabular}

Through comparison of the length values of the RIS examination type samples with length value of their corresponding examination type in the DRL, the results suggest that they were acceptable and thus, a direct mapping may be developed between these two types of examinations since the dosimetric calculations in CT examinations are currently based on these two quantities (TSALAFOUTAS, and METALLIDIS, 2011). For example, the length values obtained were 14 and $14.2 \mathrm{~cm}$ of the $\mathrm{CCT} / \mathrm{Head}$ examination type sample and in the DRL respectively. These values were found to be within the same range. This statement may be true for all other length values of the five samples in the two systems. Although the results may be considered sufficient enough for these specific five samples, however, direct mapping may not always be achievable because in many circumstances even in modern CT scanners, there are missing data since these values are not always stored within the examination archives; such as one or both of the index values in the
RIS data base and therefore, if they are not manually recorded, they might get lost (TSALAFOUTAS, and METALLIDIS, 2011).

Thus, without these indexes the formula cannot be applied for direct mapping. Another issue that may prevent mapping is that each institute has its internal standards and different names for the examination type. Therefore, if this mapping procedure is applied to another RIS from a different institute it might not achieve the same acceptable results. This is because of the variety of examination study descriptions that arise from the different names used for the same procedure (Mabotuwana et. al., 2014).

\section{Reduced RadLex List}

Table 9 shows a prototype of the reduced list; this modified list will be known as a reduced and amended Playbook list. This reduced list was attempted to overcome the direct mapping problems mentioned above, and for the need of using another standardized study description for the mapping procedure was a necessary requirement in order to improve the procedure. 
Table (9): A Prototype of the Reduced and Amended RadLex Playbook list

\begin{tabular}{|c|c|c|}
\hline EXAMINATION STUDY DESCRIPTION & LATERALITY & PHARMACEUTICAL (IV CONTRAST) \& PHASES \\
\hline CT ABDOMEN & & W,WO,BOTH,MULTIPHASE \\
\hline CT ABDOMEN ANGIOGRAPHY & & W,WO,BOTH,MULTIPHASE \\
\hline CT ABDOMEN ANGIOGRAPHY KIDNEY & & W,BOTH \\
\hline CT ABDOMEN ANGIOGRAPHY LIVER & & W,BOTH,MULTIPHASE \\
\hline CT ABDOMEN BIOPSY & & WO \\
\hline CT ABDOMEN CERVICAL SPINE & & WO \\
\hline CT ABDOMEN CHEST ANGIOGRAPHY & & W \\
\hline CT ABDOMEN CHEST LIVER & & BOTH \\
\hline CT ABDOMEN KIDNEY & BILATERAL & W,WO,BOTH,MULTIPHASE \\
\hline CT ABDOMEN LIVER & & W,WO,BOTH,MULTIPHASE \\
\hline CT ABDOMEN PANCREAS & & W.WO.BOTH,MULTIPHASE \\
\hline CT ABDOMEN PELVIS & & W,WO,BOTH,MULTIPHASE \\
\hline CT ABDOMEN PELVIS CERVICAL SPINE & & W,WO,BOTH \\
\hline CT ABDOMEN PELVIS KIDNEY & & WO,BOTH,MULTIPHASE \\
\hline CT ABDOMEN PELVIS LUMBAR SPINE & & WO \\
\hline CT BRAIN & & W,WO,BOTH \\
\hline CT BRAIN CERVICAL SPINE & & WO \\
\hline CT BRAIN FACIAL BONES & & WO \\
\hline CT CERVICAL SPINE & & W,WO,BOTH \\
\hline CT CHEST & & W,WO,BOTH,MULTIPHASE \\
\hline CT CHEST ABDOMEN & & W,WO,BOTH,MULTIPHASE \\
\hline CT CHEST ABDOMEN ANGIOGRAPHY & & W.,WO,BOTH \\
\hline CT CHEST ABDOMEN PELVIS & & W,WO,BOTH,MULTIPHASE \\
\hline CT CHEST ABDOMEN PELVIS ANGIOGRAPHY & & W,WO,BOTH \\
\hline CT CHEST ANGIOGRAPHY & & W,WO,BOTH,MULTIPHASE \\
\hline CT CHEST CERVICAL SPINE & & WO \\
\hline CT FACE FACIAL BONES & & W,WO,BOTH \\
\hline CT HEAD BRAIN & & W,WO,BOTH \\
\hline CT HEAD CERVICAL SPINE & & W,WO,BOTH \\
\hline CT HEAD CHEST ABDOMEN PELVIS & & W,WO,BOTH \\
\hline CT HEAD CHEST ABDOMEN & & WO \\
\hline CT HEAD CHEST BRAIN & & WO \\
\hline CT HEAD CHEST FACIAL BONES & & WO \\
\hline CT HEAD FACIAL BONES & & W,WO,BOTH \\
\hline CT HEAD NECK & & W,WO,BOTH \\
\hline CT HEAD NECK ANGIOGRAPHY & & W \\
\hline CT HEAD PARANASAL SINUSES & & W,WO,BOTH \\
\hline CT LUMBAR SPINE & & W,WO,BOTH \\
\hline CT LOWER EXTREMITY ANGIOGRAPHY & LEFT,RIGHT,BILATERAL & W,BOTH \\
\hline
\end{tabular}

However, the RadLex Playbook list has its own issues and that it contains more than 1000 CT scan variety examination study description types. Because of that, it made the implementation of the mapping structure very complicated to deal and work with. Therefore, to solve this problem the modified list was suggested which was extracted from the original list to facilitate the procedure by limiting and reducing some of these CT examination studies to create a new list. After applying and implementing all the suggestions and arguments points that were explained and mentioned before in the methods and materials, a modified list was achieved with a high percent of reduction that facilitated the procedure structure for mapping in order to obtain a suggested strategy method which helped towards interoperability for mapping institution-specific RIS data to the DRL values.

The obligated conditions from the reduction list was, that it should cover all important and necessary requirements of the examination protocol types and that it also could cover all common entities of the RIS and then it could be mapped completely to the DRL standard. This reduced list was tentatively called "reduced and amended RadLex Playbook list" The approach of this procedure was to establish the reduction list in which several aspects were applied according to some suggestions and arguments. One of the most obvious arguments was from the modality and the application side, where it was expected that a major part of these thousand exam types, which are available in the list, were not actually used. As a matter of fact, only a limited number of very specific and basic protocols were used. At the end after the reduction procedure, only some minor modifications were going to subsist.

In this procedure after obtaining the modified list, it was mapped to the DRL and it was considered as a suggested standardized method that could cover most cases of the examination 
types to achieve a sufficient and proper way for mapping and to get rid of the issue of restriction in resolution.

\section{RadLex List and DRL mapping}

Table 10 represent the result of a direct mapping between the modified reduced list and the DRL. This intermediate result may simplify for the radiologist the mapping between the modified reduced RadLex with the DRL in order to get to the final step.

Table 10 A prototype of mapping between the Reduced list and the DRL

\begin{tabular}{|c|c|c|c|c|}
\hline EzanIMATION STUDT DESERIP PION & Lateralutt & PHARHACEUTICAL (II CONTRAST) \& PHASES & \begin{tabular}{|l} 
DRL (EZAM STUDT REGOIM__) \\
\end{tabular} & DRL (EXAM STUDT REGOIM_Z) \\
\hline CTABDOMEN & & W,WO,BOTH,MULIPHASE & Upporatstamen & \\
\hline CTABDOMEHANGIOGRAPHY & & W,WO,BOTH,MULIIPHASE & 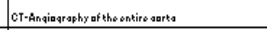 & \\
\hline CTABDOMENAHGIOGRAPHY KIOHEY & & W,BOTH & CT-Anniagrashy of tho ontirc arerta & \\
\hline CTABDOMENAMGIOGRAFHYLUER & & W.EOTH,MULTPHASE & 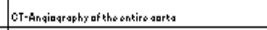 & \\
\hline CTABDOMENEIOPSY & & wo & \begin{tabular}{|l|l} 
Upper atdemen \\
\end{tabular} & \\
\hline CTABDOMENGERMCAL LFPINE & & wo & Upporatsamen & Corvisaltrine \\
\hline CTABDOMENOHEST ANGIOGGAPHY & & w & 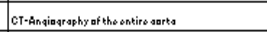 & \\
\hline CTABDOMENGHESTLWER & & ВоTH & 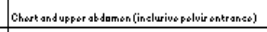 & \\
\hline CTABDOMENKKIONEY & ELLATERAL & W,WO,EOTH,MULIIPHASE & Upporobstomen & \\
\hline CTABDOMENLUYER & & W,WO,BOTH,MULTIPHASE & Upporatsemen & \\
\hline CTABDOMEHPANCREAS & & W.WO.EOTH,MULTIPHASE & Upper abdamen & \\
\hline CTABDOMENPELWIS & & W,WO,EOTH,MULTIPHASE & Abdemen uith polvir & \\
\hline CTABDOMENPELMII OERVIOALL SPIME & & W,WO,BOTH & Atsemenuith polvir & Coerviselspine \\
\hline CTABDOMENFELIISKIDNEY & & WO,EOTH,MULTIPHASE & Atsomenuith polvis & \\
\hline CTABDOMEHPELWISLUMEAF SPINE & & wo & Atdomen uith polvir & Lumbarppine \\
\hline CTERAlY & & w,WO,BOTH & Heos(trrain) & \\
\hline GTERAIIN CERMIOAL SPIHE & & wo & Hood(train) & Corviselspine \\
\hline CTERAIIFAGIILEOHES & & wo & Hosd(train) & Facialenens \\
\hline CTOERYCALL SFIME & & w, W0,вотн & Corvicallsine(thaner) & 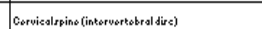 \\
\hline CTCHEST & & W,WO,BOTH,MULIIPHASE & 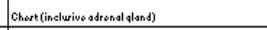 & \\
\hline CTCHEST AEDOMEN & & W,WO,BOTH,MULTPHASE & 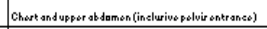 & \\
\hline CTCHEST ABDOMEMANGIIGRAPHY & & W.WO,BOTH & 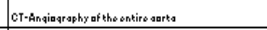 & \\
\hline CTCHESTABDOMENFELUIS & & W,WO,BOTH,MULTPHASE & 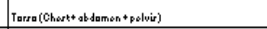 & \\
\hline CTCHEST AEDOMEN PELIIS ANGIOGRAPHY & & W,WO,BOTH & 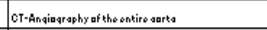 & \\
\hline CT CHEST AMGIOGRAFHY & & W,WO,BOTH,MULTIPHASE & CT-Angiagrashy yef hhe entirc arts & \\
\hline CT CHEST CERWCAL SFINE & & wo & Charer (instlwive astrenal qland) & Corvisalspine \\
\hline CTFACEFACIALBONES & & W,WO,BOTH & Fasialtanoser & \\
\hline CTHEAOERAIY & & W,WO,BOTH & Heos(brain) & \\
\hline CTHEADCERMOAL SPINE & & W,WO,BOTH & Head & Corviselatpine \\
\hline CTHEADCHESTAEDOMENFELYIS & & W,WO,EOTH & Hood & 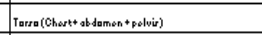 \\
\hline CTHEADCHEST AEDOMEN & & wo & Head & 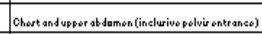 \\
\hline CTHEADCHESTERAIIM & & wo & Hood(train) & Choret (inclurivo oftenal fland) \\
\hline CTHEAD CHESTFACIAL BOHES & & wo & Fasialtanor & 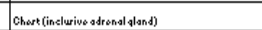 \\
\hline CTHEAOFACIALEOHES & & W, WO,BOTH & Fasialtanos & \\
\hline CTHEAOHECK & & w,wo,вотн & Head & Hock (frscialskult:ill articis arch) \\
\hline CTHEADNECKAMGIOGRAPHY & & w & CT-Angiagraphy of sarotid & \\
\hline CTHEADPARAMASAL SINUSES & & W,WO,BOTH & Paransersltinuritir & \\
\hline CTUMBEAR SPPME & & W,WO,BOTH & Lunbarrpino (bone) & 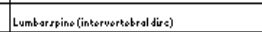 \\
\hline CTLOWER EYTREMIIYYAMGIOGRAPHY & LEFT,RIGHT,ELLATERAL & W,BOTH & 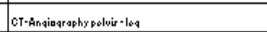 & \\
\hline
\end{tabular}

\section{Final mapping}

The final step in the procedure was showing and representing the aim of this work, which was to find general method to map between the entities of the RIS and the DRL by using another convenient standardized study description method. In the previews work, some samples of the RIS data as shown already in table 8, which were taken from the German clinic and used during the direct mapping, will be used again by using the suggested reduced list to apply a general standard method as shown in table 11 . 
Table 11 Mapping between both the RIS and DRL using the Reduced \& Amended RadLex Playbook list

\begin{tabular}{|l|l|l|l|l|l|}
\hline Examination Type (RIS) & Body Part & EXAMINATION STUDY DESCRIPTION & LATERALITY & PHARMACEUTICAL (IV CONTRAST) \& PHASES \\
\hline CCT/Head & BRAIN & CT HEAD BRAIN & & W,WO,BOTH & DRL \\
\hline Thorax nativ /Thorax & CHEST & CT CHEST & & WO & Head (Brain) \\
\hline 4 Phases Liver/Pancreas /Abdomen & ABDOMEN & CT ABDOMEN MULTIPHASE LIVER PANCREAS & & BOTH,MULTIPHASE & Chest (inclusive adrenal gland) \\
\hline Abdomen nativ/Abdomen & ABDOMEN & CT ABDOMEN & & WO & Upper abdomen \\
\hline Head-Neck-Angio /CTA & CAROTID & CT HEAD NECK ANGIOGRAPHY & & W & Cbdomen with pelvis \\
\hline
\end{tabular}

\section{CONCLUSION AND RECOMMENDATION}

Many clinical institutions were different radiology techniques are performed have their internal standards and different names for the examination types, another issue that may prevent RIS and DRL mapping.

Therefore, the role of standardization was found to be very helpful to facilitate the mapping between RIS and DRL. In this work the RadLex Playbook list was used as the standardization tool. However, the challenge was to suggest a modified list to make the RadLex Playbook more applicable for Radiologists.

In this procedure after obtaining the modified list, it was possible to map to the DRL and it was considered as a suggested standardized method that could overcome most cases of the examination types to achieve a sufficient and proper way for mapping and to avoid the issue of restriction in resolution.

\section{ACKNOWLEDGEMENT}

The authors gratefully acknowledge the contributions of THM University of Applied Sciences in Giessen as well as a German institute for providing the necessary data.

\section{REFERENCES}

(RSNA), T. R. (2017), RadLex radiology lexicon. Retrieved from http://www.rsna.org/Informatics/radlex_playb ook.cfm

A. Nitrosi, A. Corazza, M. Bertolini, R. Sghedoni, P. Pattacini, M. Iori. (2014). Patient Dose Management Solution Directly Integrated in the RIS: "Gray Detector" Software. Springer, 27(6). doi:10.1007/s10278-014-9715-y

Anushri Parakh, Mika Kortesniemi, and Sebastian T. Schindera. (2016). CT Radiation Dose Management: A Comprehensive Optimization Process for Improving Patient Safety. RSNA, 280(3). Retrieved from https://pubs.rsna.org/doi/full/10.1148/radiol.20 16151173

Commission, E. (1999). Radiation Protection 109. Retrieved from https://ec.europa.eu/energy/sites/ener/files/doc uments/109_en.pdf

Council, N. R. (2006). Health Risks from Exposure to Low Levels of Ionizing Radiation: BEIR VII . National Academies Press, 7.

Dr Sanjay Jeganathan, Dr Catherine Mandel and Dr Greg Slater. (2014). Role and Value of the Clinical Radiologist: Recognising the Value and Responding to the Challenges. The Royal Australian and New Zealand College of Radiologists (RANZCR). Retrieved from https://www.ranzcr.com/college/documentlibrary/the-role-and-value-of-the-clinicalradiologist-position-paper-full-version

EUROPEAN COMMISSION. (2018). RADIATION PROTECTION $N^{\circ}$ 185. Luxembourg: European Union. Retrieved from http://www.eurosafeimaging.org/wp/wpcontent/uploads/2018/09/rp_185.pdf

G. Stamm, H. Lenzen, M. Wucherer, G. Brix, A. Schegerer, A. Sommer, Institute for Diagnostic and Interventional Radiology Göttingen/DE, Institute of Clinical Radiology Münster/DE, Institut für Medizinische Physik Nürnberg, D/DE, Neuherberg/DE. (2017). 2nd Modification and Update of Diagnostic Reference Levels in Germany - Improvements and Consequences. EuroSafe Imaging 2017. doi:10.1594/esi2017/ESI-0034

I A TSALAFOUTAS, and S I METALLIDIS. (2011). A Method for Calculating the Dose Length Product from CT DICOM. The British Journal of Radiology. Retrieved from https://www.ncbi.nlm.nih.gov/pmc/articles/P MC3473864/

Informatics, R. (2016). RadLex Playbook 2.3 User Guide. Radiological Society of North America (RSNA).

JERROLD T. BUSHBERG, J. ANTHONY SEIBERT, EDWIN M. LEIDHOLDT JR, and JOHN M. BOONE. (2012). The Essential 
Physics of Medical Imaging. Philadelphia: Wolters Kluwer.

Kenneth C. Wang, Jigar B. Patel, Bimal Vyas, Michael Toland, Beverly Collins, Daniel J. Vreeman, Swapna Abhyankar, Eliot L. Siegel, Daniel L. Rubin, and Curtis P. Langlotz. (2017). Use of Radiology Procedure Codes in Health Care: The Need for Standardization and Structure. Radiographics: Rsna, 37(4). Retrieved from https://pubs.rsna.org/doi/full/10.1148/rg.20171 60188

L. Balkay ; A. Oszlánszki ; A. K. Krizsán. (2013, July 8). Comparison of Patient Doses at Different CT Scanners with same Acquisition Protocol. (IEEE Xplore doi:10.1109/NSSMIC.2012.6551837

Luís A. Bastião Silva ; Luís Ribeiro ; Carlos Costa ; José Luis Oliveira ; and Milton Santos. (2014, July 24). Normalizing Medical Imaging Archives for Dose Quality Assurance and Productivity Auditing. (IEEE Xplore) doi:10.1109/MeMeA.2014.6860112

Magda Bosch de Basea, Jane A. Salotti, Mark S. Pearce, Jordi Muchart, Luis Riera, Ignasi Barber, Salvador Pedraza, Marina Pardina, Antoni Capdevila, Ana Espinosa, and Elisabeth Cardis. (2015).Trends and Patterns in the use of Computed Tomography in Children and Young Adults in Catalonia Results from the EPI-CT study. Springer. doi:10.1007/s00247-015-3434-5

Morin RL, S. J. (2014). Radiation dose and safety: informatics standards and tools. NCBI, $11(12$ Pt B). doi:10.1016/j.jacr.2014.09.017

Nakada Y, Okuda Y, Tsuge T, Suzuki J, Sakamoto H, Yamamoto T, Konishi Y, Tsujimoto T, Nishiki S, Satoh T, Aoyama N, Morimoto K, Aita M, Yamashita Y, Yoshitake T, Mukai M, Yokooka Y, Yokohama N, Akahane K. (2018). AUTOMATIC ACQUISITION OF CT RADIATION DOSE DATA: USING THE DIAGNOSTIC REFERENCE LEVEL FOR RADIATION DOSE OPTIMIZATION. NCBI, 181(2). doi:10.1093/rpd/ncy003
Ozasa K, Shimizu Y, Suyama A, Kasagi F, Soda M, Grant EJ, Sakata R, Sugiyama H, Kodama K. (2011). Studies of the mortality of atomic bomb survivors, Report 14, 1950-2003: an overview of cancer and noncancer diseases. NCBI, 177(3). Retrieved from https://www.ncbi.nlm.nih.gov/pubmed/221719 60

Radiology, E. S. (2009). The Future Role of Radiology in Healthcare. Springer, 1(1). doi: 10.1007/s13244-009-0007-x

Radiology, I. I. (2016, October 14th). IR: Inside Radiology. $\quad$ Retrieved from https://www.insideradiology.com.au/diagnosti c-radiology/

Richard G. Kavanagh, John O'Grady, Brian W. Carey, Patrick D. McLaughlin, Siobhan B. O’Neill, Michael M. Maher, and Owen J. O'Connor. (2018). Low-Dose Computed Tomography for the Optimization of. Hindawi. Retrieved from https://www.hindawi.com/journals/grp/2018/1 $768716 /$

Richard Veit, and Burkhard Bauer. (2019). Introduction of Diagnostic Reference Levels into Diagnostic Radiology in Germany. Retrieved from https://www.researchgate.net/publication/2373 34441_Introduction_of_Diagnostic_Reference _Levels_into_Diagnostic_Radiology_in_Germ any

RSNA Informatics. (2016). (RSNA Informatics) Retrieved from http://radlex.org/

The Diagnostic Reference Levels (DRLs) in Europe. ( 2007, February 23rd). (ALARA) Retrieved from https://www.eualara.net/index.php/surveys-mainmenu-53/36ean-surveys/156-drls.html

Thusitha Mabotuwana, Michael C. Lee, Eric V. Cohen-Solal, and Paul Chang. (2014). Mapping Institution-Specific Study Descriptions to RadLex Playbook Entries. Springer, 27(3). Retrieved from https://link.springer.com/article/10.1007/s1027 8-013-9663-y 